Research Article

\title{
Biomonitoring of Acetylcholinesterase (AChE) Activity among Smallholder Horticultural Farmers Occupationally Exposed to Mixtures of Pesticides in Tanzania
}

\author{
Jones A. Kapeleka ${ }^{(D)},{ }^{1,2}$ Elingarami Sauli, ${ }^{1}$ Omowunmi Sadik, ${ }^{3}$ and Patrick A. Ndakidemi ${ }^{1}$ \\ ${ }^{1}$ The Nelson Mandela African Institution of Science and Technology (NM-AIST), P.O. Box 447, Arusha, Tanzania \\ ${ }^{2}$ Tropical Pesticides Research Institute (TPRI), P.O. Box 3024, Arusha, Tanzania \\ ${ }^{3}$ Binghamton University-State University of New York, Binghamton, NY 13902, USA
}

Correspondence should be addressed to Jones A. Kapeleka; jak78tz@gmail.com

Received 26 January 2019; Revised 27 May 2019; Accepted 11 August 2019; Published 11 September 2019

Academic Editor: Evelyn O. Talbott

Copyright (c) 2019 Jones A. Kapeleka et al. This is an open access article distributed under the Creative Commons Attribution License, which permits unrestricted use, distribution, and reproduction in any medium, provided the original work is properly cited.

\begin{abstract}
Biomonitoring of pesticides exposure has currently become a matter of great public concern due to the potential health effects of pesticides. This study assessed levels of acetylcholinesterase (AChE) inhibition and associated health effects in uncontrolled smallholder farming systems in rural Tanzania. A cross-sectional study was conducted of 90 exposed farmers and 61 nonexposed controls from horticultural zones. A structured questionnaire was administered, and a capillary blood sample of $10 \mu \mathrm{l}$ was used to measure AChE activity using an Erythrocyte Acetylcholinesterase Test Mate Photometric Analyzer kit (Model 400). A multiple logistic regression model was used to investigate determinants of pesticide exposure. The study revealed that smallholder farmers are occupationally exposed to pesticides. Exposed farmers had significantly lower AChE levels. The use of personal protective equipment (PPE) did not significantly reduce the likelihood of AChE inhibition. Women, younger and older farmers, and underweight, overweight, and obese farmers were at increased risk of AChE inhibition. Increase in age (10 years) increased likelihood of $\mathrm{AChE}$ inhibition by $6.7 \%$, while decrease in BMI increased likelihood of AChE inhibition by $86.7 \%$ while increased pesticides contact hours increased risk of having lower AChE at about 3 times. The number of exposure symptoms $(14.10 \pm 7.70)$ was higher in exposed farmers than unexposed. Self-reported symptoms are confirmed to correlate to lower AChE. Prevalence of tiredness (71.6\% against $15.5 \%)$, fatigue (64.8\% against $27.6 \%)$, soreness in joints $(59.1 \%$ against $20.7 \%)$, thirst (52.3\% against $12.1 \%$ ), skin irritation (52.1\% against $17.2 \%)$, salivation and abdominal pain (50\% against $8.6 \%$ and $31.0 \%$, respectively), muscle weakness (47.7\% against $24.1 \%$ ), and memory loss (47.7\% against and $29.3 \%$ ) differed significantly between exposed and control. This study provides useful information regarding the level of occupational and environmental exposure to pesticides in smallholder horticultural production systems. Pesticides use needs to be controlled at farm level by developing pesticides monitoring and surveillance systems.
\end{abstract}

\section{Introduction}

The use of pesticides in controlling crop pests and boost agriculture production had increased in the recent past due to their rapid knockdown effect [1]. Smallholder horticultural production systems constitute the main subsector where pesticides are highly used. The uncontrolled nature, poor usage of personal protection equipment and lack of adequate knowledge about pesticide use results in serious health consequences [2].
Organophosphates (OPs) and carbamates (CA) are the most used families of pesticides [3-5]. These chemical compounds are antiacetylcholinesterase and endocrinedisrupting substances. OPs and CA exert their toxicity by interfering with the normal function of acetylcholine hydrolysis, a necessary task for synaptic response and an essential neurotransmitter in the autonomic and central nervous system [6,7]. High exposure to these chemicals results in neurotoxicity as well as decreased acetylcholinesterase (AChE) activity [8-10]. Hormonal changes, 
abnormal sperm, ovaries and eggs production, neurological, gastrointestinal, dermatological, and respiratory manifestations among many other effects are associated with acetylcholine inhibition due to organophosphorus pesticides exposure $[11,12]$.

People who have direct and prolonged contact with pesticides have more risk of exposure [13]. Increased risk of exposure is a result of pesticides accumulation on the clothing, skin, and boots after spraying in the field as well as inhalation exposures through spray residue and spray drift [14]. Spraying pesticides in mixtures as opposed to recommended spraying practice on the pesticides labels foster occupational exposure $[1,15]$.

In evaluating potential human exposure to chemicals that act as cholinesterase inhibitors, erythrocyte blood cholinesterase $(\mathrm{AChE})$ testing is done to establish the levels of exposure $[10,16,17]$. AChE inhibition provides a useful biomarker of pesticides exposure and toxicity in human body and is more indicative of the severity of pesticides poisoning $[18,19]$. But owing to the fact that interindividual variability in $\mathrm{AChE}$ biomonitoring is much higher than intraindividual variability in $\mathrm{ChE}$ among the normal population [20], a single measure taken to establish the levels of severity of exposure may overestimate or underestimate the actual exposure.

Currently, few AChE studies from Tanzania had been conducted in traditional cash crops, including coffee, commercialized tea estates, and flower industries targeting exposed farmers only [21, 22]. In one study, no significant difference in the levels of AChE among 133 coffee and cotton smallholder farmers between farming (spraying) and nonfarming (nonspraying) season was reported [21]. Furthermore, farmers in commercialized tea estates and flower industries were occupationally exposed to pesticides, but unexposed control groups were not included in both cases. The most recent study conducted in Arusha assessed the health symptoms of pesticides exposure among flower and onion pesticides applicators indicated neurological health symptoms and AChE inhibition [23]. The available studies assessed exposed farmers only and household survey data to examine the health effects of pesticide exposure; hence, the need to use objective methods to evaluate health effects of pesticide exposure using unexposed individuals as control group.

Due to the differences in levels of exposure, type of pesticides used, regulatory mechanisms, pesticides mixture compositions, geographical behaviors, and demographic characteristics of the farming population areas, it is difficult to generalize and compare the published studies [24, 25]. The aim of this study was, therefore, to assess the comparative levels of pesticides exposure by determining the AChE levels and factors influencing pesticides exposure in smallholder horticultural in Tanzania, to describe pesticides-handling practices and risk behaviors and to derive an association between AChE inhibition and self-reported symptoms. The study compares levels of exposure and self-reported symptoms with AChE levels between farmers and control group, complementing previous studies where unexposed control groups were not included.

\section{Materials and Methods}

2.1. Study Design. This was a comparative cross-sectional study conducted among 90 farmers occupationally exposed to pesticides and 61 healthy individuals (control group) with similar socioeconomic characteristics. Participants were selected from the general population for controlling the effects of confounding factors including lifestyles, exposure to X-rays, eating habits, inter and intraindividual variations, weather, and geographical characteristics on AChE inhibition. However, the study tried to minimize these limitations by purposive selection of the control group with matching demographic characteristics and geographical locations as well as adjusting for age and BMI in the multivariate analysis. This comparative use of control groups in drawing conclusive evidence of pesticides exposure had been reported in several studies [8, 10, 26-30].

2.2. Sample Size and Sampling Procedure. Kilolo (Iringa) and Ngarenanyuki (Arusha) were purposely selected based on horticultural productivity and extensive use of synthetic pesticides. Horticultural farmers were randomly selected from the list of households provided by respective village government officers. The sample was chosen based on the proportion of farmers involved in smallholder horticultural production. According to the Tanzania 2012 Population and Housing Census, Kilolo recorded 218,130 while Ngarenanyuki 20,379 farmers.

Inclusion criteria included individuals who are occupationally involved in pesticides handling and working in a sprayed field, had sprayed during the last week before survey, or had weeded/harvest field sprayed with pesticides during the same period. Exclusion criteria included individuals who are not involved directly in handling pesticides or not working in pesticides-related activities. The control group was purposely selected based on the criteria that none of them had been recently exposed to agrochemicals or previous occupational exposure to pesticides and matched with age, sex, and other demographic variables. This group included office employees and shopkeepers living in the same region as exposed individuals.

The sample size used in this study was based on previous studies which indicated that a minimum sample size of 30 farmers would be sufficient to detect a difference in cholinesterase activity between farming and nonfarming groups and that of 90 yields power over $80 \%[10,17]$. A total of 90 exposed and 90 unexposed individuals were recruited. From the unexposed group, 29 individuals did not meet the inclusion criteria and, therefore, were removed from the sample. Hence, a sample size of 61 unexposed individuals was used.

2.3. Data Collection. A structured questionnaire containing both closed- and open-ended questions was administered to participants for a health survey. The questionnaire used in the previous study [21] was used with minor modifications to suit the current research. This improved questionnaire was further pretested among 20 individuals from one village in the study areas, which was finally removed from the 
sample. Collected information included pesticides used, pesticides use practices and handling, frequency of application, areas sprayed, use of PPE, and exposure risk behaviors. Demographic information and farmer habits and lifestyles (age, gender, alcohol consumption, and smoking) were also collected. Assessment of exposure symptoms to OPs and CA was done through a random list of 38 different symptoms typical to OPs and CA exposure. Anthropometric measurement (height and weight) were also taken to determine the body mass index (BMI), which was calculated and categorized using four WHO criteria for underweight, normal, overweight, and obese. Field observations were done to observe pesticides mixing, handling, type of PPE used, and disposal methods of empty pesticides containers.

\section{Determination of Acetylcholinesterase (AChE) Inhibition}

3.1. Blood Samples Collection and Handling. Collection of blood was carried out according to the procedures explained by Cotton et al. [17] and Neupane et al. [10]. The Erythrocyte Acetyl cholinesterase Test Mate Photometric Analyzer kit (Model 400) was used to test the cholinesterase inhibition based on manufactures' standard methodology [31], whereby a capillary blood sample of $10 \mu \mathrm{l}$ was used to measure AChE activity standardized against whole blood haemoglobin. This haemoglobin-adjusted erythrocyte acetylcholinesterase activity $(Q)$ was measured in $(\mathrm{U} / \mathrm{g} \mathrm{Hb})$ and used to describe the levels of exposure.

3.2. Data Analysis. Statistical analysis of data was done using SPSS 22.0 computer software. Descriptive statistics such as frequencies, percentages, mean, and standard deviations were performed to summarize the characteristics for the study population, and results are presented as (mean \pm standard deviation). Association of risk behaviors including smoking, eating, and use of PPE, BMI, and haemoglobin-adjusted erythrocyte acetylcholinesterase activity (Q) was done using chi-squared testing. One-way ANOVA testing was used to determine factors influencing haemoglobin-adjusted erythrocyte acetylcholinesterase activity $(Q)$ among exposed and control subjects, which was dichotomized into two categories. The first category is "inhibition" (24.5-31.3 U/g Hb), and the second is "severe inhibition" ( $<24.5 \mathrm{U} / \mathrm{g} \mathrm{Hb})$. The cutoff point of exposure set at $24.5 \mathrm{U} / \mathrm{g} \mathrm{Hb}$ was used. This is the recommended guidelines from the Tropical Pesticides Research Institute (TPRI), which is the regulatory threshold level indicating exposure (TPRI, 2000). Student's $t$-tests were used to compare the significant difference in the levels of exposure between farmers and control groups while the chi-square test was used to test association between the symptoms and AChE inhibition.

Multiple logistic regression analysis with the outcome variable, the probability of having low AChE level, was used to determine the critical explanatory factors for AChE inhibition. Significant level for the results was accepted at $p<0.05$. The following logistic regression model with dummy variables to control for any individual differences was developed:

pesticides exposure $=f($ age $, \mathrm{BMI}, \mathrm{WEP}, \mathrm{AAS}, \mathrm{CHP}, \mathrm{SBP}, \varepsilon)$,

where pesticides exposure is the measure of AChE inhibition indicated by low or high $Q$ level, as dichotomized at one SD below the mean Q, i.e., at the $25.2 \mathrm{U} / \mathrm{g} \mathrm{Hb}$. For the explanatory variables, age is the age category of farmers, BMI is the WHO body mass index categories, WEP is the working experience with pesticides, and AAS is the average area sprayed per day in acres. Furthermore, CHP is the contact (working) hours with pesticides, SBP is the spraying break period before embarking on another intensive spraying season, and $\varepsilon$ denote the unknown variables.

3.3. Ethical Clearance. Ethical clearance was obtained from Tanzania's National Institute of Medical Research (NIMR) with Reference No. NIRM/HQ/R.8a/Vol.IX/2742. Both farmers and unexposed individuals each signed a written consent form for a blood test and participation in the research.

\section{Results}

The study involved 108 participants from Iringa (71.5\%) and 43 from Arusha (28.5\%) regions in Tanzania, where smallholder horticultural production is highly practiced. In drawing comparative results from exposure, 90 exposed farmers (59.6\%) and 61 control groups (40.4\%) were involved in the study. The farming population was found to be generally younger. The dominant age group was between 30 and 39 years, while the mean age was $(38.74 \pm 12.72)$ years (mean $\pm \mathrm{SD}$ ), dominated by men $(73.5 \%)$ compared with women (26.5\%). Just above half (53.6\%) had been working with pesticides for over ten years and (27.5\%) for 5-9 years, as presented in Table 1, showing the demographic characteristics of the study population.

Organophosphorus (97.6\%) and carbamate (54.1\%) pesticides constitute the main chemical families of pesticides used in horticultural production consisting mainly of insecticides (69.0\%) and fungicides (30.1\%). Others include substituted benzene, pyrethroids, and organochlorines (Table 2). Furthermore, $85.5 \%$ of all registered pesticides used to fall under Class II (Moderately hazardous) WHO hazard classification of pesticides, while the rest falls under WHO Class $U$ (unlikely to present acute hazard in regular use).

The use of personal protective equipment (PPE) was not common among farmers. None of the farmers had complete body protection, and most $(85.7 \%)$ were partially protected, while $14.3 \%$ were completely unprotected. Gumboots were the major PPE widely used by farmers (83.3\%). Nonetheless, farmers in onion production did not wear gumboots completely to avoid the destruction of onion bulbs. Moreover, gloves $(92.9 \%)$, respirators $(95.2 \%)$, masks $(90.5 \%)$, goggles (97.6\%), and overalls/overcoats (92.3\%) were not used during pesticides handling (Table 3 ). The $t$-test showed 
TABLE 1: Demographic characteristics of the study population.

\begin{tabular}{lcc}
\hline Variable & $n$ & $\%$ \\
\hline Region of respondent & & \\
$\quad$ Iringa (Kilolo) & 108 & 71.5 \\
$\quad$ Arusha (Ngarenanyuki) & 43 & 28.5 \\
Category of respondent & & \\
$\quad$ Exposed & 90 & 59.6 \\
$\quad$ Unexposed (control) & 61 & 40.4 \\
Age category of respondent & & \\
30-39 years & 43 & 28.5 \\
20-29 years & 35 & 23.2 \\
40-49 years & 32 & 21.2 \\
50-59 years & 26 & 17.2 \\
60 years and above & 9 & 6.0 \\
Less than 20 years & 6 & 4.0 \\
Sex of respondent & & \\
Male & 111 & 73.5 \\
Female & 40 & 26.5 \\
Working experience with pesticides & & 53.6 \\
10 years and above & 37 & 27.5 \\
5-9 years & 19 & 17.4 \\
1-4 years & 12 & 1.4 \\
Less than one year & 1 & 100.0 \\
Total & 69 & \\
\hline
\end{tabular}

TABLE 2: Chemical families of pesticides used in horticultural production.

\begin{tabular}{lcc}
\hline Variable & $n$ & $\%$ \\
\hline Chemical families & & \\
Organophosphorus & 285 & 97.6 \\
Carbamate & 158 & 54.1 \\
Substituted benzene & 101 & 34.6 \\
Pyrethroid + organophosphorus & 84 & 28.8 \\
Avermectin & 82 & 28.1 \\
Carbamate + acylalanine & 67 & 22.9 \\
Dithiocarbamate & 57 & 19.5 \\
Inorganic fungicide & 39 & 13.4 \\
Pyrethroid & 26 & 8.9 \\
Organochlorine & 26 & 8.9 \\
Pyrethroid + nitroimidazole & 25 & 8.6 \\
Oxadiazines & 12 & 4.1 \\
Conazole & 6 & 2.1 \\
Propionic acid & 5 & 1.7 \\
\hline
\end{tabular}

no statistical difference in the AChE inhibition between farmers without protection and those who partially covered themselves during spraying $(p=0.711)$.

Results from the AChE tests show that exposed farmers had a decreased AChE activity $(28.05 \pm 3.88 \mathrm{U} / \mathrm{g} \mathrm{Hb})$ compared with the control group $(32.87 \pm 4.36 \mathrm{U} / \mathrm{g} \mathrm{Hb})$. The AChE inhibition of exposed farmers (67.8\%) recorded 24.5-31.3 U/g Hb compared with the control group (39.3\%). Furthermore, $15.6 \%$ of exposed farmers had AChE levels less than $24.5 \mathrm{U} / \mathrm{g} \mathrm{Hb}$ compared with none in the control group (Table 4). The difference in the levels of exposure was statistically significant $(p<0.001)$ between exposed and control group, signifying occupational exposure to pesticides. AChE levels in women mainly involved in weeding and harvesting of horticultural crops were lower compared with exposed
TABLE 3: Farmers' use of personal protection equipment (PPE).

\begin{tabular}{lcc}
\hline Variable & $n$ & $\%$ \\
\hline Wear gloves when spraying pesticides & & \\
No & 78 & 92.9 \\
Yes & 6 & 7.1 \\
Total & 84 & 100.0 \\
Wear boots when spraying pesticides & & \\
Yes & 70 & 83.3 \\
No & 14 & 16.7 \\
Total & 84 & 100.0 \\
Wear a respirator when spraying pesticides & & \\
No & 80 & 95.2 \\
Yes & 4 & 4.8 \\
Total & 84 & 100.0 \\
Wear a mask when spraying pesticides & & \\
No & 76 & 90.5 \\
Yes & 8 & 9.5 \\
Total & 84 & 100.0 \\
Wear goggles when spraying pesticides & & \\
No & 82 & 97.6 \\
Yes & 2 & 2.4 \\
Total & 84 & 100.0 \\
Wear head covers when spraying pesticides & & \\
No & 78 & 92.9 \\
Yes & 6 & 7.1 \\
Total & 84 & 100.0 \\
Wear overall when spraying pesticides & & \\
No & 12 & 92.3 \\
Yes & 1 & 7.7 \\
Total & 13 & 100.0 \\
\hline
\end{tabular}

men and their counterpart women from the control group (Table 5).

Body mass index (BMI) influenced farmers' exposure to pesticides. Exposed farmers with low BMI had significantly lower AChE levels. Half (50\%) of exposed farmers under WHO underweight category $\left(\mathrm{BMI}<18.5 \mathrm{~kg} / \mathrm{m}^{2}\right)$ recorded AChE $<24.5 \mathrm{U} / \mathrm{g} \mathrm{Hb}$ compared with only $7.9 \%$ of exposed but with normal BMI $\left(18.50-24.99 \mathrm{~kg} / \mathrm{m}^{2}\right)$. Chi-square tests showed a statistically significant association between exposure levels measured by $Q$ and BMI within the exposed group $(p=0.004)$. Furthermore, AChE inhibition showed a statistically significant trend that varied with BMI categories $(p<0.001)$. AChE activity was much depressed for underweight $(26.73 \pm 5.56 \mathrm{U} / \mathrm{g} \quad \mathrm{Hb})$, overweight $(27.32 \pm 4.95 \mathrm{U} / \mathrm{g} \mathrm{Hb})$, and obese $(21.90 \mathrm{U} / \mathrm{g} \mathrm{Hb})$ as opposed to normal BMI-exposed individuals $(28.37 \pm 3.32 \mathrm{U} / \mathrm{g} \mathrm{Hb})$, as presented in Table 6 .

Age of farmers influenced cholinesterase inhibition among exposed farmers. AChE levels were lower in younger farmers less than 20 years $(23.08 \pm 2.84 \mathrm{U} / \mathrm{g} \mathrm{Hb})$, and much older farmers aged 60 years and above $(25.20 \pm 2.34 \mathrm{U} / \mathrm{g} \mathrm{Hb})$ compared with the middle-aged farmers of $30-39$ years and $40-49$ years $(29.88 \pm 3.58 \mathrm{U} / \mathrm{g} \mathrm{Hb}$ and $28.63 \pm 6.34 \mathrm{U} / \mathrm{g} \mathrm{Hb})$ respectively (Table 7 ). The association between age and AChE inhibition was statistically significant $(p=0.046)$, suggesting the vulnerability of younger and older ages on increased pesticide exposure risks. The analysis of variance (ANOVA) test showed that farmers' exposure to pesticides did not significantly differ among farmers with different 
TABle 4: Categories of pesticides poisoning.

\begin{tabular}{|c|c|c|c|c|c|c|c|}
\hline \multirow{3}{*}{ Category of pesticide poisoning } & \multicolumn{4}{|c|}{ Category of respondent } & \multirow{2}{*}{\multicolumn{2}{|c|}{ Total }} & \multirow{3}{*}{$p$ value } \\
\hline & \multicolumn{2}{|c|}{ Exposed } & \multicolumn{2}{|c|}{ Unexposed } & & & \\
\hline & $n$ & $\%$ & $n$ & $\%$ & $n$ & $\%$ & \\
\hline $24.5-31.3 \mathrm{U} / \mathrm{g} \mathrm{Hb}$ & 61 & 67.8 & 24 & 39.3 & 85 & 56.3 & \\
\hline$\geq 31.4 \mathrm{U} / \mathrm{g} \mathrm{Hb}$ & 15 & 16.7 & 37 & 60.7 & 52 & 34.4 & \\
\hline$<24.5 \mathrm{U} / \mathrm{g} \mathrm{Hb}$ & 14 & 15.6 & & & 14 & 9.3 & $p<0.001$ \\
\hline Total & 90 & 100.0 & 61 & 100.0 & 151 & 100.0 & \\
\hline
\end{tabular}

TABle 5: Comparative levels of AChE inhibition.

\begin{tabular}{|c|c|c|c|c|c|c|c|c|}
\hline \multirow{5}{*}{ Variable } & \multicolumn{8}{|c|}{ Category of respondent } \\
\hline & \multirow{2}{*}{\multicolumn{4}{|c|}{$\begin{array}{c}\text { Exposed } \\
\text { Sex of respondent }\end{array}$}} & \multicolumn{4}{|c|}{ Unexposed (control) } \\
\hline & & & & & \multicolumn{4}{|c|}{ Sex of respondent } \\
\hline & \multicolumn{2}{|c|}{ Male } & \multicolumn{2}{|c|}{ Female } & \multicolumn{2}{|c|}{ Male } & \multicolumn{2}{|c|}{ Female } \\
\hline & Mean & $\mathrm{SD}$ & Mean & SD & Mean & SD & Mean & $\mathrm{SD}$ \\
\hline Cholinesterase inhibition ( $\mathrm{U} / \mathrm{g} \mathrm{Hb})$ & 28.38 & 3.49 & 26.86 & 4.95 & 32.76 & 4.48 & 33.08 & 4.21 \\
\hline
\end{tabular}

TABLE 6: Relationship between BMI and cholinesterase inhibition of exposed farmers.

\begin{tabular}{|c|c|c|c|c|c|c|c|c|c|c|}
\hline \multirow{3}{*}{ Variable } & \multicolumn{8}{|c|}{ WHO BMI classification } & & \\
\hline & \multicolumn{2}{|c|}{$\begin{array}{c}\text { Underweight } \\
(<18.5)\end{array}$} & \multicolumn{2}{|c|}{$\begin{array}{c}\text { Normal } \\
(18.50-24.99)\end{array}$} & \multicolumn{2}{|c|}{$\begin{array}{l}\text { Overweight } \\
(25-29.99)\end{array}$} & \multicolumn{2}{|c|}{ Obese $(>30)$} & \multicolumn{2}{|c|}{ Total } \\
\hline & Mean & $\mathrm{SD}$ & Mean & $\mathrm{SD}$ & Mean & $\mathrm{SD}$ & Mean & $\mathrm{SD}$ & Mean & $\mathrm{SD}$ \\
\hline Cholinesterase inhibition (U/g Hb) & 26.73 & 5.56 & 28.37 & 3.32 & 27.32 & 4.95 & 21.90 & - & 27.97 & 3.89 \\
\hline
\end{tabular}

working experience and handling of pesticides $(p=0.737)$. However, exposed farmers with working experience of 14 years in spraying and handling of pesticides had slightly lower AChE $(28.82 \pm 2.97 \mathrm{U} / \mathrm{g} \mathrm{Hb})$ compared with those worked between 5 and 9 years $(30.69 \pm 3.23 \mathrm{U} / \mathrm{g} \mathrm{Hb})$ and above ten years $(30.47 \pm 5.07 \mathrm{U} / \mathrm{g} \mathrm{Hb})$, but the difference was not statistically significant.

Logistic regression analysis results presented in Table 8 show that an increase in age (10 years interval) increases risks of lower AChE by $6.7 \%$ (odds ratio $(\mathrm{OR})=1.067 ; 95 \%$ CI: $0.864 ; 1.319)$ while the $1 \%$ decrease in BMI increases the probability of risk of having low AChE levels by $86.7 \%$ $(\mathrm{OR}=0.867 ; 95 \% \mathrm{CI}: 0.502 ; 1.496)$. The decrease in average farm area sprayed per day decreases the probability of farmers having lower AChE levels ( $\mathrm{OR}=0.001 ; 95 \% \mathrm{CI}$ : $0.000 ; 0.372$ ). Farmers with long working hours have the probability of about three times of having lower AChE levels (OR=3.497; 95\% CI: $1.080 ; 11.322)$.

Risk behaviors analysis showed that farmers were aware of and avoided exposure risks behaviors. Eating, smoking, and drinking while spraying were not common behaviors among farmers. Only $22.6 \%$ and $27.4 \%$ of the farmers ate and drank during pesticides spraying, respectively. Likewise, smoking was not prevalent; $96.4 \%$ did not smoke during pesticides spraying (Table 9). There were no statistical differences in the cholinesterase inhibition levels among farmers who ate $(p=0.171)$ and drank $(p=0.069)$ and those who smoked during spraying $(p=0.156)$.

A total of 38 clinical manifestations, which are typical symptoms for organophosphates and carbamates exposure, were reported by farmers. Exposed farmers reported more exposure symptoms than the control group $(14.10 \pm 7.70$ against $6.48 \pm 6.62$ respectively). Additionally, $40.9 \%$ of exposed farmers reported 10-19 exposure symptoms as opposed to $27.6 \%$ from the control group. On the contrary, none of the exposed farmers reported no exposure symptom while $24.1 \%$ of individuals from the control reported no exposure symptoms. More than a quarter (27.3\%) of exposed farmers reported 20 and above exposure symptoms of pesticides exposure (Table 10). There was no significant difference in the number of exposure symptoms between farmers who partially covered and those totally uncovered during pesticides handling $(p=0.217)$.

The most reported exposure symptoms which differed significantly between the exposed and control group include tiredness $(71.6 \%$ versus $15.5 \%)$, fatigue $(64.8 \%$ versus $27.6 \%$ ), soreness in joints ( $59.1 \%$ versus $20.7 \%)$, thirst $(56.8 \%$ versus $12.1 \%)$, headache and weakness ( $52.3 \%$ versus $34.5 \%)$, skin irritation (51.1\% versus $17.2 \%$ ), salivation (50.0\% versus $8.6 \%)$, and abdominal pain (50.0\% versus $31.0 \%)$ as shown in Table 11. A comparative analysis between the exposed and control indicated a statistically significant difference in the number of exposure symptoms reported $(p<0.001)$. Symptoms for which there was no expected association with exposure to cholinesterase inhibitors were not found more commonly in the exposed farmers. These included loss of appetite, lacrimation, loss of consciousness, and vomiting being not directly linked to exposure symptoms. Only those which significantly differed between the two groups were attributed to pesticides exposure. 
TABLE 7: Relationship between age categories and cholinesterase inhibition.

\begin{tabular}{|c|c|c|c|c|c|c|c|c|c|c|c|c|c|}
\hline \multirow{3}{*}{ Variable } & \multicolumn{13}{|c|}{ Age category of respondent } \\
\hline & \multicolumn{2}{|c|}{$\begin{array}{l}\text { Less than } \\
20 \text { years }\end{array}$} & \multicolumn{2}{|c|}{$20-29$ years } & \multicolumn{2}{|c|}{$30-39$ years } & \multicolumn{2}{|c|}{$40-49$ years } & \multicolumn{2}{|c|}{$50-59$ years } & \multicolumn{2}{|c|}{$\begin{array}{c}60 \text { years and } \\
\text { above }\end{array}$} & \multirow[t]{2}{*}{$p$ value } \\
\hline & Mean & SD & Mean & SD & Mean & SD & Mean & SD & Mean & SD & Mean & $\mathrm{SD}$ & \\
\hline Cholinesterase inhibition (U/g Hb) & 23.08 & 2.84 & 27.74 & 2.85 & 29.88 & 3.58 & 28.63 & 4.58 & 26.55 & 4.00 & 25.20 & 2.43 & 0.046 \\
\hline
\end{tabular}

TABLE 8: Logistic regression analysis for determinants of the outcome variable $(\mathrm{AChE}<24.5 \mathrm{Ug} / \mathrm{Hb})$.

\begin{tabular}{|c|c|c|c|c|c|c|}
\hline \multirow{2}{*}{ Independent variables } & \multirow{2}{*}{$B$} & \multirow{2}{*}{$Z$-values } & \multirow{2}{*}{ Sig. } & \multirow{2}{*}{ Odd ratios } & \multicolumn{2}{|c|}{$95.0 \% \mathrm{CI}$} \\
\hline & & & & & Lower & Upper \\
\hline Age categories & 0.065 & 0.367 & 0.045 & 1.067 & 0.864 & 1.319 \\
\hline BMI categories & -0.143 & 0.262 & 0.008 & 0.867 & 0.502 & 1.496 \\
\hline $1-4$ yrs working with pesticides & -1.369 & 0.292 & 0.589 & 0.254 & 0.002 & 36.495 \\
\hline 5-yrs working with pesticides & -1.614 & 0.570 & 0.450 & 0.199 & 0.003 & 13.147 \\
\hline Average area spread/day & -6.620 & 5.309 & 0.021 & 0.001 & 0.000 & 0.372 \\
\hline Working hours/day & 1.252 & 4.363 & 0.037 & 3.497 & 1.080 & 11.322 \\
\hline $\begin{array}{l}\text { Break less than a month before next intensive spray } \\
\text { period }\end{array}$ & -0.763 & 0.126 & 0.723 & 0.466 & 0.007 & 31.497 \\
\hline $\begin{array}{l}\text { Break for 1-2 months before next intensive spray } \\
\text { period }\end{array}$ & -2.580 & 0.979 & 0.322 & 0.076 & 0.000 & 12.551 \\
\hline Constant & -2.792 & 0.044 & 0.835 & 0.061 & & \\
\hline
\end{tabular}

TABle 9: Pesticides exposure risk practices.

\begin{tabular}{lcc}
\hline Variable & $n$ & $\%$ \\
\hline Eat while dealing with pesticides & & \\
$\quad$ No & 65 & 77.4 \\
Yes & 19 & 22.6 \\
Total & 84 & 100.0 \\
Drinking while dealing with pesticides & & \\
No & 61 & 72.6 \\
Yes & 23 & 27.4 \\
Total & 84 & 100.0 \\
Smoking while dealing with pesticides & & \\
No & 81 & 96.4 \\
Yes & 3 & 3.6 \\
Total & 84 & 100.0 \\
\hline
\end{tabular}

TABLE 10: Comparative categories of reported signs and symptoms.

\begin{tabular}{lcccccc}
\hline & \multicolumn{4}{c}{ Category of } & \multicolumn{2}{c}{ Total } \\
Variable & $\begin{array}{c}\text { respondent } \\
\text { Exposed }\end{array}$ & Control & & \\
& $n$ & $\%$ & $n$ & $\%$ & $n$ & $\%$ \\
\hline Categories of number of symptoms & & & & \\
$1-9$ symptoms & 28 & 31.8 & 25 & 43.1 & 53 & 36.3 \\
$10-19$ symptoms & 36 & 40.9 & 16 & 27.6 & 52 & 35.6 \\
20 symptoms and above & 24 & 27.3 & 3 & 5.2 & 27 & 18.5 \\
No exposure symptoms & & & 14 & 24.1 & 14 & 9.6 \\
Total & 88 & 100.0 & 58 & 100.0 & 146 & 100.0 \\
\hline
\end{tabular}

Furthermore, the results show statistically significant association $(p<0.001)$ between the number of exposure symptoms and the level of AChE inhibition. This indicates that farmers with more symptoms are more likely to have lower levels of AChE (Table 12).

\section{Discussion}

This study found that organophosphates and carbamate pesticides constitute the main pesticides used. But these pesticides are reported to be responsible for the bulk of acute poisoning cases $[32,33]$. Similar pesticides have been previously reported in Tanzania [21, 34], Brazil [35], Australia [17], and Nepal [10]. Both organophosphate and carbamate pesticides are cholinesterase-inhibiting chemicals that induce neurotoxic effects. Previous studies have reported that occupational exposure to a mixture of OPs and CA results in decreased acetylcholinesterase (AChE) activity [9]. The low levels of AChE revealed among the exposed farmers indicate that there was exposure to OPs, carbamates, or a mixture of both OPs and carbamates.

Lower AChE levels in exposed farmers are significantly associated with DNA damage, reactive oxygen stress (ROS), and increased micronuclei frequencies [5, 10, 36-38], indicating that exposed farmers with significantly lower AChE are at risk of genotoxic effects of pesticides exposure. Similar findings had been reported previously [9, 28, 32, 39], but the levels observed in this study are slightly smaller than AChE inhibition reported among Indonesian farmworkers [40]. On the contrary, findings from Iowa and North Carolina, as well as Australia, showed no statistical difference in the AChE levels between the exposed and unexposed individuals $[17,41]$. This may be explained by the fact that most farmers in developing countries rely on the use of pesticides that are relatively cheaper but highly toxic while the use of pesticides is highly regulated and monitored in developed countries.

A difference in the level of exposure between men and women was noted. Women farmers, mainly involved in weeding and harvesting of horticultural crops, were more exposed than men in this study, supporting women vulnerability to OPs and CA exposure. These findings support previous studies from Thailand, India, and 
TABLE 11: Self-reported exposure signs and reported symptoms.

\begin{tabular}{|c|c|c|c|c|}
\hline \multirow{3}{*}{ Variable } & \multicolumn{4}{|c|}{ Category of respondent } \\
\hline & \multicolumn{2}{|c|}{ Treatment } & \multicolumn{2}{|c|}{ Control } \\
\hline & $n$ & $\%$ & $n$ & $\%$ \\
\hline Tiredness & 63 & 71.6 & 9 & 15.5 \\
\hline Fatigue & 57 & 64.8 & 16 & 27.6 \\
\hline Soreness in joints & 52 & 59.1 & 12 & 20.7 \\
\hline Thirst & 50 & 56.8 & 7 & 12.1 \\
\hline Headache & 46 & 52.3 & 20 & 34.5 \\
\hline Weakness & 46 & 52.3 & 11 & 19.0 \\
\hline Skin irritation & 45 & 51.1 & 10 & 17.2 \\
\hline Salivation & 44 & 50.0 & 5 & 8.6 \\
\hline Abdominal pain & 44 & 50.0 & 18 & 31.0 \\
\hline Muscle weakness & 42 & 47.7 & 14 & 24.1 \\
\hline Memory loss & 42 & 47.7 & 17 & 29.3 \\
\hline Excessive sweating & 40 & 45.5 & 9 & 15.5 \\
\hline Blurred vision & 40 & 45.5 & 18 & 31.0 \\
\hline Blurred vision associated with excessive tearing & 38 & 43.2 & 15 & 25.9 \\
\hline Eye irritation & 37 & 42.0 & 8 & 13.8 \\
\hline Nervousness & 35 & 39.8 & 15 & 25.9 \\
\hline Moodiness & 34 & 38.6 & 14 & 24.1 \\
\hline Perspiration & 34 & 38.6 & 12 & 20.7 \\
\hline Irritation of the nose and throat & 33 & 37.5 & 6 & 10.3 \\
\hline Productive cough & 33 & 37.5 & 11 & 19.0 \\
\hline Drooling & 31 & 35.2 & 12 & 20.7 \\
\hline Chest pain & 31 & 35.2 & 5 & 8.6 \\
\hline Dizziness & 30 & 34.1 & 14 & 24.1 \\
\hline Loss of appetite & 28 & 31.8 & 22 & 37.9 \\
\hline Muscle twitches & 28 & 31.8 & 8 & 13.8 \\
\hline Red eyes & 28 & 31.8 & 11 & 19.0 \\
\hline Nausea & 27 & 30.7 & 7 & 12.1 \\
\hline Restlessness & 26 & 29.5 & 13 & 22.4 \\
\hline Shortness of breath & 24 & 27.3 & 6 & 10.3 \\
\hline Skin rash & 21 & 23.9 & 3 & 5.2 \\
\hline Tremor & 20 & 22.7 & 3 & 5.2 \\
\hline Lacrimation & 20 & 22.7 & 13 & 22.4 \\
\hline Loss of weight & 18 & 20.5 & 6 & 10.3 \\
\hline Diarrhea & 14 & 15.9 & 4 & 6.9 \\
\hline Loss of consciousness & 9 & 10.2 & 5 & 8.6 \\
\hline Vomiting & 7 & 8.0 & 4 & 6.9 \\
\hline Confusion & 5 & 5.7 & 3 & 5.2 \\
\hline Convulsions & 3 & 3.4 & & \\
\hline
\end{tabular}

TABle 12: Chi-square test for the association between number of exposure symptoms and AChE inhibition.

\begin{tabular}{|c|c|c|c|}
\hline & Value & df & $p$ value \\
\hline Pearson chi-square & 438.000 & 93 & $p<0.001$ \\
\hline Continuity correction & & & \\
\hline Likelihood ratio & 371.564 & 93 & $p<0.001$ \\
\hline Linear-by-linear association & 127.415 & 1 & $p<0.001$ \\
\hline No. of valid cases & 146 & & \\
\hline
\end{tabular}

Indonesia [14, 42, 43]. Women are more exposed than pesticide applicators, possibly because safety training and the use of PPE are usually lower, and the duration of exposure may be higher than that of the applicators. Likewise, women are thought to do less risky work; hence, they get less protection from pesticides exposure $[25,44]$.

Susceptibility to pesticides exposure is also enhanced by their larger relative fat mass; thus, larger distribution volume for lipophilic organophosphates, which are exceptionally prone to storage in fat tissue [45]. The alarming cholinesterase inhibition among women compared with men justifies further studies on their genetic damage from possible genotoxicity of pesticide exposure. Further studies are also required to investigate pesticide effects on women fertility levels and coexposure of women and their children as women tend to work while their babies are close.

A trend in nutrition status against exposure levels was observed. Farmers with low BMI (underweight) and higher BMIs (Overweight and obese) had significantly lower AChE levels. The observed variations in the levels of exposure may be directly associated with impaired body functioning for undernourished and overnourished individuals. A need for further studies on involved mechanisms for these results is further warranted, including genotoxicity analysis among groups with different nutrition status. 
Eating and smoking increase the risks of oral exposure. These risk behaviors, including drinking during pesticides handling, were not a common practice for the farmers. Only $22.6 \%$ of the farmers reported eating during pesticides spraying. This is much lower than the proportion of farmers (60\%) reported in a previous study from Benin [5]. Lack of significant difference in the level of exposure between farmers who reported eating and smoking and those who did not, therefore, show that the main route of exposure was through dermal exposure. Farmers avoiding eating and smoking during spraying indicate their awareness on the risk behaviors.

From the demographic parameters investigated, age influenced AChE levels. The variation was observed between younger and older farmers with younger and older farmers significantly having lower AChE levels compared with middle-aged farmers. This is contrary to the reported study in Benin [5] where the age of the farmers did not significantly influence the level of AChE. Enzymes involved in the metabolism of pesticides may be highly susceptible to inhibition to the immature immunity (the youth) and compromised immunity (older adults), suggesting that body immunity may be a predisposing factor for vulnerability and susceptibility to pesticides exposure.

Farmers' exposure to pesticides did not differ significantly with the working period of farmers in handling pesticides. These findings are not in support of a previous study in Pakistan [46] that reported strong relationship with duration of work in agriculture and chlorpyrifos and endosulfan levels. The observed similarities in exposure levels among farmers with different working experience with pesticides may be attributed to poor pesticides use practices. Both experienced and unexperienced farmers are equally exposed to pesticide-deriving similar health effects. Likewise, exposure patterns may have changed as its not known whether they used Cholinesterase inhibitors consistently.

Increasing the area sprayed was found to increase the probability of lower AChE levels. As expected, farmers with long working hours have high exposure risks. Increasing operation time results in increased pesticides contact hours, which ultimately fosters the rate of dermal exposure from wet cloths and leaking spraying equipment, which were observed in the field. Likewise, nonstatistically significant association was observed whereby exposure risks were relatively high among farmers who sprayed without break because the time required to liberate the enzyme (AChE) from inhibition is more than the time necessary for the synthesis of a new enzyme, which is more than 30 days after exposure [46]. Farmers breaking more than a month have more time for the enzyme recovery and metabolic detoxification of OPs. Breaking for a reasonable period before embarking on intensive spraying season can reduce the level of exposure among farmers.

Farmers' pesticides handling practices were observed to increase risks of pesticides exposure. The health effects of pesticides exposure observed in this current study may be partly attributed to poor personal protective equipment (PPE). The use of PPE is an essential aspect of personal protection against exposure because most organophosphates are highly lipid-soluble agents and are well absorbed from the skin [25]. The results from this study show that the use of PPE did not significantly reduce pesticides exposure. Insignificant difference between the partially and unprotected farmers suggests that PPE is not effectively used because effective use of PPE had been reported to reduce health hazards from pesticides $[6,47,48]$. Poor use and quality of the PPE used may also account for their insignificant contribution in reducing exposure among farmers.

The general population is environmentally exposed to pesticides due to the modest AChE inhibition in the controls. Similar findings had been previously reported in Pakistan, where non-farmers were found to be exposed [49]. Dietary exposure is assumed to be the main route of exposure. Consumption of pesticides-contaminated crops and the availability of pesticides in the environments resulting from poor disposal of obsolete and empty pesticides containers may account for this exposure, which warrants a critical assessment of safety of horticultural crops locally produced and consumed in Tanzania.

More exposure symptoms were reported among the exposed compared with the control group similar to previous results reported in Nepal, Vietnam, and Indonesia $[10,43]$. However, the number reported in this study is far above the average number of symptoms in literature reviewed $[6,50]$. High prevalence of tiredness, fatigue, soreness in joints, thirst, skin irritation, salivation and abdominal pain, muscle weakness, and memory loss indicate chronic and neurotoxic effects associated with deficits in neurobehavioral performance and abnormalities in nerve functioning [51]. The statistically significant association between the number of symptoms and the level of AChE, and the fact that our "dummy" symptoms were not elevated; this confirms that the observed symptoms emanated from occupational exposure to pesticides. Consequently, the statistically significant difference in the number of symptoms between exposed and control groups further shows that farmers are occupationally exposed to pesticides in the study areas, raising a public health concern for the farming community.

\section{Conclusion}

Of recent, there had been no biomonitoring exposure evaluation of this kind done by comparing the exposed and unexposed in Tanzania. This study provides evidence of exposure to pesticides in uncontrolled smallholder horticultural production systems. The decreased levels of AChE and positive association with a number of exposure symptoms in exposed farmers signify that the health effects of pesticides exposure are real among the farming population in Tanzania. Women, young (less than 20 years) and older farmers (60 years and above), those with lower BMI, and obese were all at increased risk of pesticide exposure. Decrease in AChE levels among the control group indicates that the general population is at risk of pesticides environmental exposure due to the presence of pesticides in the environment, food chain, and water. 
Pesticides use therefore needs to be controlled both for workers and for nonworking populations exposed through other routes of environmental contamination by developing pesticides monitoring and surveillance systems. Capacity building for women workers, in particular, on self-protection and observance of pre-entre and reentre periods, should be emphasized in the farming communities. Policy on regular monitoring of pesticides exposure is vital. Inclusion of pesticides exposure in national health and epidemiological surveys to consider pesticides exposure as a public health concern among the farming population will raise public awareness of pesticides exposure.

\section{Data Availability}

The legal requirements of the research permit as per the National Institute of Medical Research (NIMR) restrict public sharing and access of raw data for ethical concerns. However, authors requiring data may contact the corresponding author for assistance.

\section{Conflicts of Interest}

The authors declare that there are no conflicts of interest regarding the publication of this paper.

\section{Authors' Contributions}

JK participated in the designing of the study and wrote the description of the analytical method used, involved in data collection, collection of samples, sample analysis, conducted statistical analysis, and wrote the first draft of the manuscript. ES participated in the design of the study and supervision of sample collection, and provided valuable insight into the preparation of the first draft of the manuscript. OS was involved in giving insights, data interpretation, and refining of the manuscript. PN supervised the whole research work, participated in the design of the study, supervised the statistical analysis, and provided valuable insight for revising the manuscript. All authors have read and approved the manuscript.

\section{Acknowledgments}

The authors convey sincere appreciations to district agricultural officers of Iringa and Arusha, village extension officers, and health officers in Kilolo and Ngarenanyuki for organizing farmers and facilitating collection and storage of biological samples. The authors also extend their heartfelt thanks to the National Institute of Medical Research (NIMR) in Tanzania for granting permission and ethical clearance to conduct this study. The research team acknowledges the Tropical Pesticides Research Institute (TPRI) for providing technical and lab facilities during the field survey and laboratory tests. The study was funded by the Centre for Research, Agricultural Advancement, Teaching Excellence and Sustainability in Food and Nutritional Security (CREATES) at the Nelson Mandela African Institution of Science and Technology (NM-AIST), Arusha, Tanzania.

\section{References}

[1] C. A. Damalas and M. Khan, "RETRACTED: pesticide use in vegetable crops in Pakistan: insights through an ordered probit model," Crop Protection, vol. 99, pp. 59-64, 2017.

[2] M. M. Mattah, P. A. D. Mattah, and G. Futagbi, "Pesticide application among farmers in the catchment of Ashaiman Irrigation Scheme of Ghana: health implications," Journal of Environmental and Public Health, vol. 2015, Article ID 547272, 7 pages, 2015.

[3] W. J. Ntow, H. J. Gijzen, P. Kelderman, and P. Drechsel, "Farmer perceptions and pesticide use practices in vegetable production in Ghana," Pest Management Science, vol. 62, no. 4 , pp. 356-365, 2006.

[4] A. V. F. Ngowi, T. J. Mbise, A. S. M. Ijani, L. London, and O. C. Ajayi, "Smallholder vegetable farmers in Northern Tanzania: pesticides use practices, perceptions, cost and health effects," Crop Protection, vol. 26, no. 11, pp. 1617-1624, 2007.

[5] H. A. Vikkey, D. Fidel, Y. P. Elisabeth et al., "Risk factors of pesticide poisoning and pesticide users' cholinesterase levels in cotton production areas: Glazoué and savè townships, in central Republic of Benin," Environmental Health Insights, vol. 11, pp. 1-10, 2017.

[6] S. Dasgupta, C. Meisner, D. Wheeler, K. Xuyen, and N. Thi Lam, "Pesticide poisoning of farm workers-implications of blood test results from Vietnam," International Journal of Hygiene and Environmental Health, vol. 210, no. 2, pp. 121-132, 2007.

[7] G. V. Rao and M. Jyothsna, "Serum cholinesterase levels in organophosphorous poisoning patients on ventilatory support," Indian Journal of Clinical Anaesthesia, vol. 3, no. 1, pp. 52-55, 2016.

[8] J. Da Silva, C. R. Moraes, V. D. Heuser et al., "Evaluation of genetic damage in a Brazilian population occupationally exposed to pesticides and its correlation with polymorphisms in metabolizing genes," Mutagenesis, vol. 23, no. 5, pp. 415422, 2008.

[9] S. Singh, V. Kumar, S. Thakur et al., "DNA damage and cholinesterase activity in occupational workers exposed to pesticides," Environmental Toxicology and Pharmacology, vol. 31, no. 2, pp. 278-285, 2011.

[10] D. Neupane, E. Jørs, and L. Brandt, "Pesticide use, erythrocyte acetylcholinesterase level and self-reported acute intoxication symptoms among vegetable farmers in Nepal: a cross-sectional study," Environmental Health, vol. 13, no. 98, pp. 1-7, 2014.

[11] N. Arya, "Pesticides and human health:Why public health officials should support a ban on non-essential residential use," Canadian Journal of Public Health, vol. 96, no. 2, pp. 89-92, 2005.

[12] J. A. Bhalli, Q. M. Khan, and A. Nasim, "DNA damage in Pakistani pesticide-manufacturing workers assayed using the comet assay," Environmental and Molecular Mutagenesis, vol. 47 , no. 8, pp. 587-593, 2006.

[13] R. C. Gilden, K. Huffling, and B. Sattler, "Pesticides and health risks," Journal of Obstetric, Gynecologic \& Neonatal Nursing, vol. 39, no. 1, pp. 103-110, 2010.

[14] A. Guytingco, P. Thepaksorn, and R. L. Neitzel, "Prevalence of abnormal serum cholinesterase and associated symptoms from pesticide exposure among agricultural workers in the south of Thailand," Journal of Agromedicine, vol. 23, no. 3, pp. 270-278, 2018. 
[15] W. J. Ntow, The Use and Fate of Pesticides in Vegetable-Based Agroecosystems in Ghana, CRC Press, London, UK, 1st edition, 2008.

[16] P. Knechtges, An Evaluation of Blood Cholinesterase Testing Methods for Military Health Surveillance, United States Army Center for Environmental Health Research, Fort Detrick, MD, USA, 2008, https://apps.dtic.mil/dtic/tr/fulltext/u2/a482707. pdf.

[17] J. Cotton, J. Edwards, M. A. Rahman, and S. Brumby, "Cholinesterase research outreach project (CROP): point of care cholinesterase measurement in an Australian agricultural community," Environmental Health, vol. 17, no. 31, pp. 1-11, 2018.

[18] M. Lotti, "Cholinesterase inhibition: complexities in interpretation," Clinical Chemistry, vol. 41, no. 12, pp. 18141818, 1995.

[19] D. Rathish, I. Senavirathna, C. Jayasumana, and S. Agampodi, "Red blood cell acetylcholinesterase activity among healthy dwellers of an agrarian region in Sri Lanka: a descriptive cross-sectional study," Environmental Health and Preventive Medicine, vol. 23, no. 1, pp. 4-9, 2018.

[20] A. Brock and V. Brock, "Factors affecting inter-individual variation in human plasma cholinesterase activity: body weight, height, sex, genetic polymorphism and age," Archives of Environmental Contamination and Toxicology, vol. 24, no. 1, pp. 93-99, 1993.

[21] A. V. Ngowi, Health impact of exposure to pesticides in agriculture in Tanzania, Ph.D. dissertation, Tampere University Press, Tampere, Finland, 2002, https://trepo.tuni.fi/bitstream/handle/ 10024/67224/951-44-5456-1.pdf?sequence=1\&isAllowed $=\mathrm{y}$.

[22] J. A. Kapeleka, E. E. Lekei, and T. Hagali, "Pesticides exposure and biological monitoring of ache activity among commercial farm workers in Tanzania : a case of tea estates," International Journal of Science and Research, vol. 5, no. 9, pp. 1708-1713, 2016.

[23] S. G. Mwabulambo, E. J. Mrema, A. Vera Ngowi, and S. Mamuya, "Health symptoms associated with pesticides exposure among flower and onion pesticide applicators in Arusha region," Annals of Global Health, vol. 84, no. 3, pp. 369-379, 2018.

[24] C. Martínez-Valenzuela, S. Gómez-Arroyo, R. VillalobosPietrini et al., "Genotoxic biomonitoring of agricultural workers exposed to pesticides in the north of Sinaloa State, Mexico," Environment International, vol. 35, no. 8, pp. 1155-1159, 2009.

[25] C. Damalas and S. Koutroubas, "Farmers' exposure to pesticides: toxicity types and ways of prevention," Toxics, vol. 4, no. 1, p. 1, 2016.

[26] P. Grover, K. Danadevi, M. Mahboob et al., "Evaluation of genetic damage in workers employed in pesticide production utilizing the comet assay," Mutagenesis, vol. 18, no. 2, pp. 201-205, 2003.

[27] Y.-J. Liu, P. L. Huang, Y. F. Chang et al., "GSTP1 genetic polymorphism is associated with a higher risk of DNA damage in pesticide-exposed fruit growers," Cancer Epidemiology Biomarkers \& Prevention, vol. 15, no. 4, pp. 659-666, 2006.

[28] R. Naravaneni and K. Jamil, "Determination of AChE levels and genotoxic effects in farmers occupationally exposed to pesticides," Human \& Experimental Toxicology, vol. 26, no. 9, pp. 723-731, 2007.

[29] R. McKinlay, J. A. Plant, J. N. B. Bell, and N. Voulvoulis, "Calculating human exposure to endocrine disrupting pesticides via agricultural and non-agricultural exposure routes,"
Science of The Total Environment, vol. 398, no. 1-3, pp. 1-12, 2008.

[30] J. A. Bhalli, T. Ali, M. R. Asi, Z. M. Khalid, M. Ceppi, and Q. M. Khan, "DNA damage in Pakistani agricultural workers exposed to mixture of pesticides," Environmental and Molecular Mutagenesis, vol. 50, no. 1, pp. 37-45, 2009.

[31] EQM Research Inc., Test-Mate ChE Cholinesterase Test System (Model 400) Instruction Manual, EQM Research Inc., Cincinnati, OH, USA, 2003.

[32] A. P. Remor, C. C. Totti, D. A. Moreira, G. P. Dutra, V. D. Heuser, and J. M. Boeira, "Occupational exposure of farm workers to pesticides: biochemical parameters and evaluation of genotoxicity," Environment International, vol. 35, no. 2, pp. 273-278, 2009.

[33] E. E. Lekei, A. V. Ngowi, and L. London, "Farmers' knowledge, practices and injuries associated with pesticide exposure in rural farming villages in Tanzania," BMC Public Health, vol. 14, pp. 1-13, 2014.

[34] L. A. Mtashobya and B. Nyambo, "Levels of pesticide residues in the eastern arc mountains part of Tanzania," International Journal of AgriScience, vol. 4, no. 10, pp. 452-462, 2014.

[35] A. C. P. Silvério, L. Azevedo, D. A. Nogueira et al., "Assessment of exposure to pesticides in rural workers in southern of Minas Gerais, Brazil," Environmental Toxicology and Pharmacology, vol. 55, pp. 99-106, 2017.

[36] K. Atreya, B. Kumar Sitaula, H. Overgaard, R. Man Bajracharya, and S. Sharma, "Knowledge, attitude and practices of pesticide use and acetylcholinesterase depression among farm workers in Nepal," International Journal of Environmental Health Research, vol. 22, no. 5, pp. 401-415, 2012.

[37] G. Ji, Y. Xia, A. Gu et al., "Effects of non-occupational environmental exposure to pyrethroids on semen quality and sperm DNA integrity in Chinese men," Reproductive Toxicology, vol. 31, no. 2, pp. 171-176, 2011.

[38] K. M. Kasiotis, K. Kyriakopoulou, C. Emmanouil et al., "Monitoring of systemic exposure to plant protection products and DNA damage in orchard workers," Toxicology Letters, vol. 210, no. 2, pp. 182-188, 2012.

[39] H. Vivien, Z. Hashim, P. Ismail et al., "Biological monitoring of genotoxicity to organophosphate pesticide exposure among rice farmers: exposure-effect continuum study," Journal of Occupational Health and Epidemiology, vol. 2, no. 1, pp. 2736, 2013.

[40] Suratman, Risk factors for organophosphate pesticide (OP) exposure among indonesian and south australian migrant farmworkers and the impact of an intervention to reduce exposure, Ph.D. thesis, Flinders University, Bedford Park, Australia, 2015, https://flex.flinders.edu.au/file/a4c92846-e528-4b26-ab745fedf153473a/1/PhD_THESIS-SURATMAN(2101570).pdf.

[41] C. Sanford, D. Sabapathy, H. Morrison, and K. Gaudreau, "Pesticides and human health. Systematic review, part I. Heal wellness," 2015, https://www.princeedwardisland.ca/sites/ default/files/publications/cpho_pesticide_part_1.pdf.

[42] F. Mancini, A. H. C. Van Bruggen, J. L. S. Jiggins, A. C. J. Ambatipudi, and H. Murphy, "Acute pesticide poisoning among female and male cotton growers in India," International Journal of Occupational and Environmental Health, vol. 11, no. 3, pp. 221-232, 2005.

[43] H. H. Murphy, A. Sanusi, R. Dilts, S. Yuliatingsih, M. Djajadisastra, and N. Hirschhorn, "Health effects of pesticide use among Indonesian women farmers," Journal of Agromedicine, vol. 6, no. 3, pp. 61-85, 2008.

[44] L. London, S. De Grosbois, C. Wesseling, S. Kisting, H. A. Rother, and D. Mergler, "Pesticide usage and health 
consequences for women in developing countries: out of sight out of mind?," International Journal of Occupational and Environmental Health, vol. 8, no. 1, pp. 46-59, 2002.

[45] M. E. Butter, "Are women more vulnerable to environmental pollution?," Journal of Human Ecology, vol. 20, no. 3, pp. 221-226, 2006.

[46] D. J. Ecobichon, "Pesticide use in developing countries," Toxicology, vol. 160, no. 1-3, pp. 27-33, 2001.

[47] U. Ündeǧer and N. Başaran, "Assessment of DNA damage in workers occupationally exposed to pesticide mixtures by the alkaline comet assay," Archives of Toxicology, vol. 76, no. 7, pp. 430-436, 2002.

[48] M. Koureas, A. Tsakalof, M. Tzatzarakis, E. Vakonaki, A. Tsatsakis, and C. Hadjichristodoulou, "Biomonitoring of organophosphate exposure of pesticide sprayers and comparison of exposure levels with other population groups in Thessaly (Greece)," Occupational and Environmental Medicine, vol. 71, no. 2, pp. 126-133, 2014.

[49] Y. Latif, S. T. H. Sherazi, M. I. Bhanger, S. Nizamani, and S. Nizamani, "Evaluation of pesticide residues in human blood samples of agro professionals and non-agro professionals," American Journal of Analytical Chemistry, vol. 3, no. 8, pp. 587-595, 2012.

[50] M. Khan and C. A. Damalas, "Occupational exposure to pesticides and resultant health problems among cotton farmers of Punjab, Pakistan," International Journal of Environmental Health Research, vol. 25, no. 5, pp. 508-521, 2015.

[51] M. C. R. Alavanja, J. A. Hoppin, and F. Kamel, "Health effects of chronic pesticide exposure: cancer and neurotoxicity," Annual Review of Public Health, vol. 25, no. 1, pp. 155-197, 2004. 


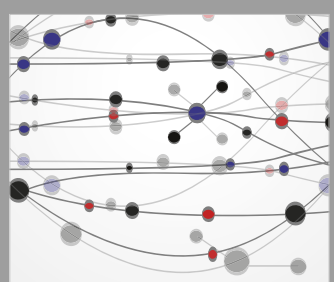

The Scientific World Journal
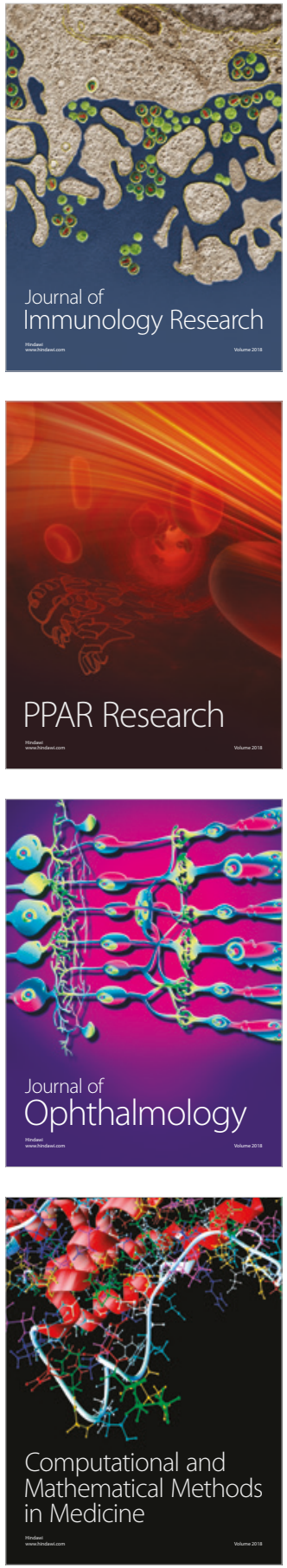

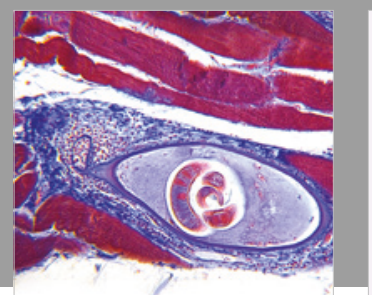

Gastroenterology Research and Practice

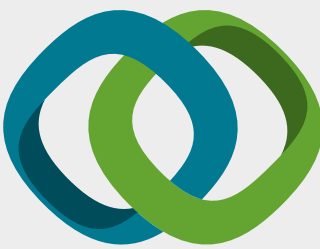

\section{Hindawi}

Submit your manuscripts at

www.hindawi.com
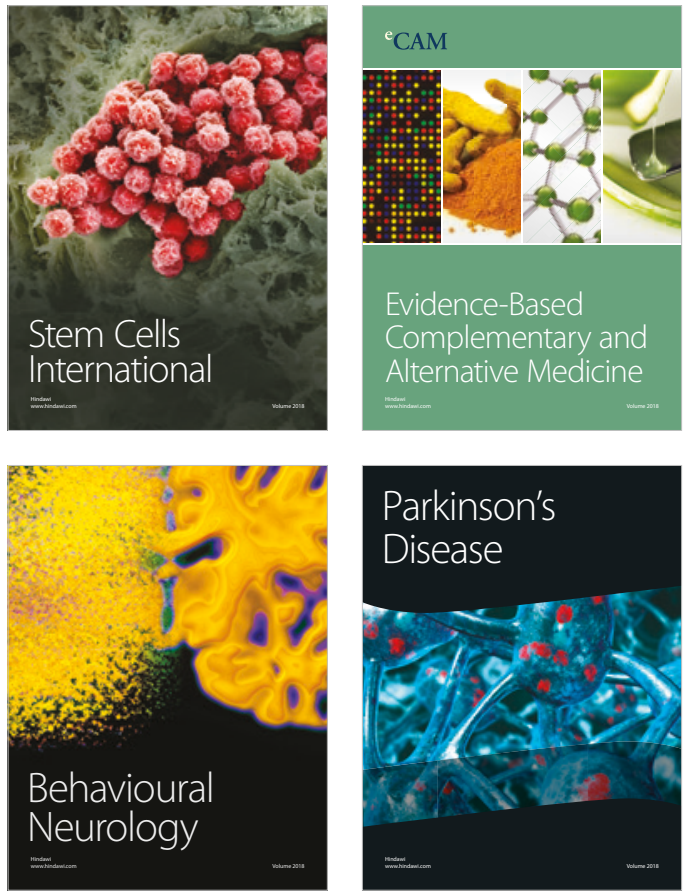

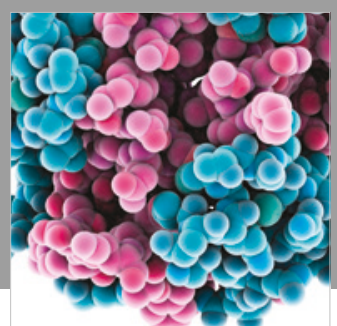

ournal of

Diabetes Research

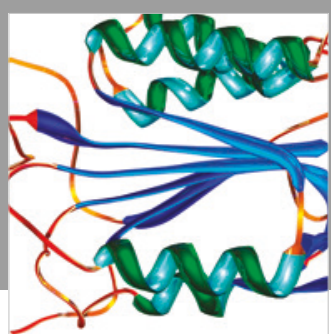

Disease Markers
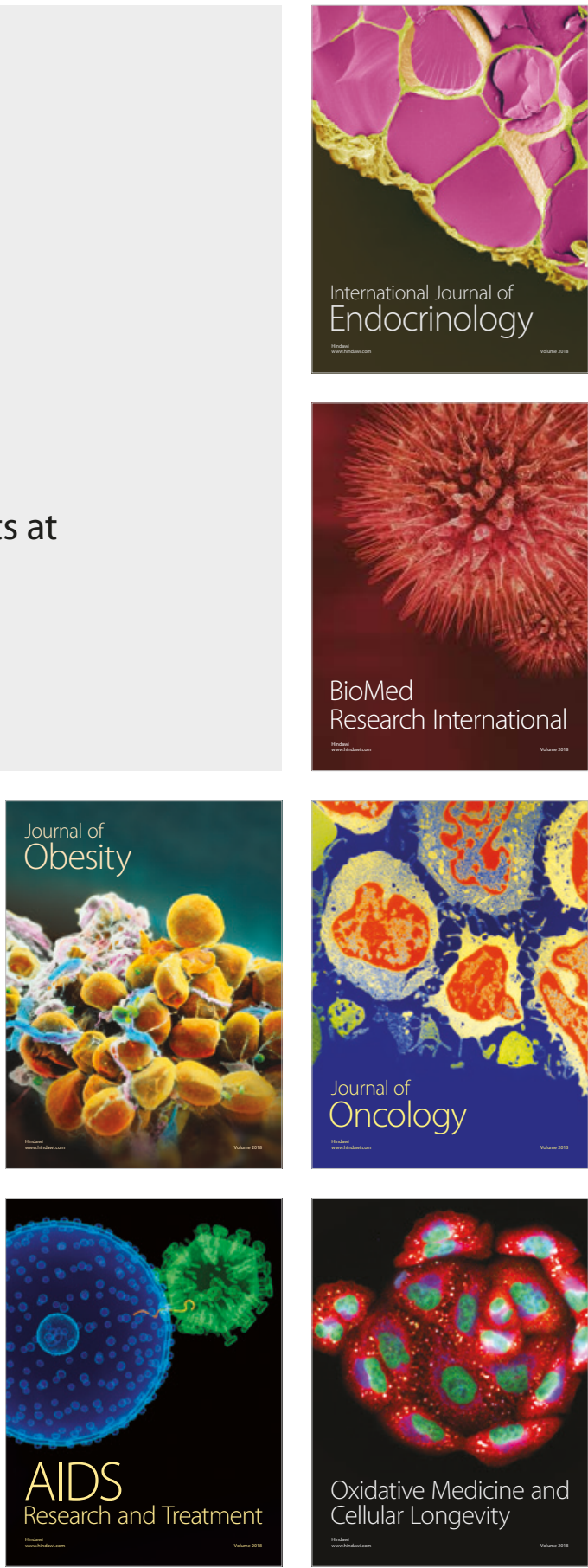